\title{
Study on Effects of Social Networks usage on PG Students
}

\author{
Dr. Sudhakar D. Bhoite1, Miss Snehal A. Patil², Miss Nisha S. Patil² \\ ${ }^{1}$ Associate Professor, Department M.phil Commerce \& Management, ${ }^{2}$ M.com \\ ${ }_{1,2}$ Chhatrapati Shahu Institute of Business Education and Research, Kolhapur, Maharashtra, India
}

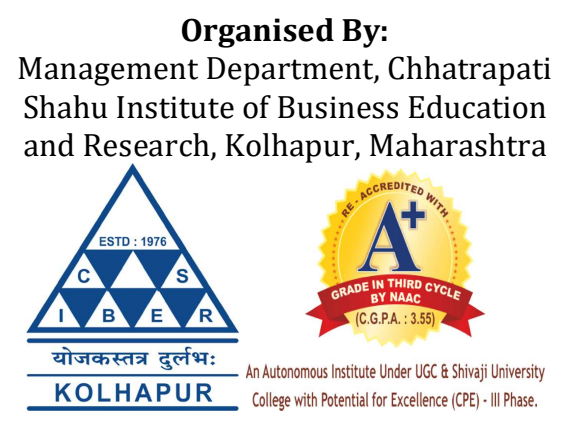

How to cite this paper: Dr. Sudhakar D. Bhoite | Miss - Snehal A. Patil | Miss Nisha S. Patil "Study on Effects of Social Networks Usage on PG Students" Published in International Journal of Trend in Scientific Research and Development (ijtsrd), ISSN: 2456-6470, Special Issue | Fostering Innovation, Integration and Inclusion Through Interdisciplinary Practices in Management, March 2019, pp.113-115, URL: https://www.ijtsrd .com/papers/ijtsrd 23078.pdf

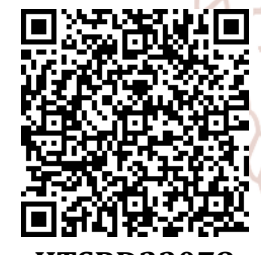
IJTSRD23078

\section{ABSTRACT}

In the business world- the uses of ICT has been increased to such an extent that all the businesses are revolving the terms like- cloud computing big data, internet of things (IOT) and effective uses of social network media. Due to dramatic changes in the communication arena, which has made drastic impact on the every aspects of human life. The education sector has also been witnessing a severe impact of social media and networks.

Social networks has now become a consistent platform for today's learners as a medium of sharing the thoughts, ideas, feeling and assisting in connecting friends, people, relatives and also as a learners platform.

\section{INTRODUCTION}

\section{What is social network?}

Social networks are internet-based activity. Social network is helpful for users for share information and conversations. There are so many social networks like Whatsapp, Face book, Instagram, LinkedIn, Snap chat, Twitter as well as Hike. There are also concerns that social networking increases the likelihood of new risks to the self. The social networks use for many reasons. Generally, users are able to post personal information, including videos, photographs. The social networking in groups, community, marketing, search, friends, accounts, messages, services, media, like and share.

Uses of Social Networking -

$>$ Connecting to people-People gather with each other. Network is the connecting people to sharing ideas and thoughts.

$>$ Linking of friends, relatives, professionals, college Mets and family members

$>$ Exchange Information (Sending, receiving data, files, messages, images, videos, music, text material etc.)

$>$ Innovation and new ideas(Knowing about new happenings, new innovations, new trends, new tools, technologies, gadgets, recent updates in the learning areas)

$>$ Status updating in society.

Social networks as source of employment such as LinkedIn are major resources that of job recruits take advantage of when looking to hire potential employees.
Effect of Social Networks-

Social networking technologies also allow one to share a thought with another It helps a man toward one side of the world to interface and trade thoughts with a man at the other side. With the use of social media students can easily communicate or share information quickly with each other through various social networking sites like Face book, What's app, and Instagram etc.

There are two types of effect -

A. Positive Effect-
B. Negative Effect
A. Positive Effect of Social Networks on Education -

1. Socialize with each other-

We grow up with the society and people as well as we make friends. Why it's important because it's help for sharing or exchanging ideas and learn more new things. This will constant result in them becomes more confident in life

2. Knowledge sharing-

It gives an easy and effective way to students can sharing knowledge. They can access information, study, and transfer. It is smooth process. 
International Journal of Trend in Scientific Research and Development (IJTSRD) @ www.ijtsrd.com eISSN: 2456-6470

3. Updating our self-

They will have the capacity to know new things as and when it happens. This causes them refresh their own particular information base.

4. Learning from different sources -

With the help of social networks we can learn easy and effectively. It's global way of learning in now days. Digital learning also useful in students life.

5. Sharing feelings and thoughts-

Students frequently don't get the right stage to share their feelings. Through social networking technologies they are given an option to sound their thoughts. If students were permitted to share what they think and feel, it becomes simple for them to decide what is good and what is bad.

B. Negative effect of Social Networks on Education

1. Mitigate learning and research abilities-

Students are not using their ability in learning. They are using the Social Networks for few searching study related material. They have own ability, but they are not using properly.

2. Decrease in real human contact -

The students are using their valuable time in Social Networks. They are going in stress, because they wastage their time in not return or profitable things. They are not giving time to their parents also. They are not contacting face to face with others. Now, Day to day decreasing in relationship abilities in student's life. They are not mingle with each other.

3. Wastage of valuable time-

Students, while seeking and concentrate on the web, get pulled in to utilizing online networking locales and once in a while they overlook why they are using internet. Sometimes students are not able to deliver their work in the specified time frame as their time wastes

4. Wastage of Learning time-

Students are not aware about how much time they are using in social networks. Students are unable to use their ability in study. In the college also students are using social networks in lecture time also. They are not aware about their study; it's also effect on their exam score.

\section{Effect on health-}

The unnecessary use of social networks has an effect on the physical health and mental. Students are not taking rest properly because of use of social networks. They are distract from study. When they are in class but they are not giving attention on study. They become unmotivated and lazy.

\section{Objectives -}

$>$ To identifying the various social networks are being used by the postgraduate students.

To determine for what purpose and how much time they spend for using social networks.

To know the students opinions about the role of social networks for academic purposes.

Table No.1 Social Network usage by PG students

\begin{tabular}{|c|c|c|c|c|}
\hline Sr. No. & Social Networks & Male & Female & Total \\
\hline 1. & Whatsapp Se & $27(54 \%)$ & $23(46 \%)$ & 50 \\
\hline 2. & Facebookeve & $26(57 \%)$ & $20(43 \%)$ & 46 \\
\hline 3. & Instagram & $24(52 \%)$ & $22(48 \%)$ & 46 \\
\hline 4. & LinkedIn & $15(48 \%)$ & $16(52 \%)$ & 31 \\
\hline 5. & Hike & $18(58 \%)$ & $13(42 \%)$ & 31 \\
\hline 6. & Twitter & $10(83 \%)$ & $2(17 \%)$ & 12 \\
\hline 7. & Snapchat & $10(43 \%)$ & $13(57 \%)$ & 23 \\
\hline
\end{tabular}

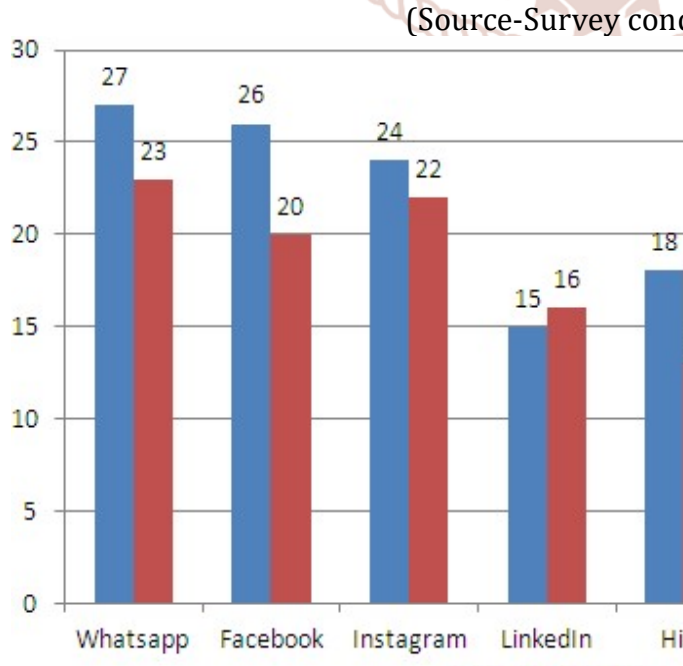

Social Networks

The above table shows data about usage of Social Networks by PG students. Out of the total it shows that $54 \%$ males students are using whatsapp, whereas $46 \%$ females students are making use of whatsapp. In case of Face book users $57 \%$ males students are using an around $43 \%$ female students prepare Face book as a social media network.

In case of Twitter as a Social Network we found that $83 \%$ male students are making use of Twitter as social network, whereas meagerly $17 \%$ female students make use of Twitter. 
International Journal of Trend in Scientific Research and Development (IJTSRD) @ www.ijtsrd.com eISSN: 2456-6470

So overall it is shows that most of the male students make use of Whatsapp (54\%) and Face book (57\%) social network where are female students prefer whatsapp (46\%).

Table No.2 Reasons for uses of Social Networks

\begin{tabular}{|c|c|c|c|c|}
\hline Sr. No & Uses of Social Networks & Male & Female & Total \\
\hline 1. & Study Purpose & $27(54 \%)$ & $23(46 \%)$ & 50 \\
\hline 2. & News & $22(56 \%)$ & $17(44 \%)$ & 39 \\
\hline 3. & Find Employment & $25(61 \%)$ & $16(39 \%)$ & 41 \\
\hline 4. & Entertainment & $27(54 \%)$ & $23(46 \%)$ & 50 \\
\hline 5. & Online Shopping & $15(43 \%)$ & $20(57 \%)$ & 35 \\
\hline 6. & Meet Friends & $27(54 \%)$ & $23(46 \%)$ & 50 \\
\hline
\end{tabular}

(Source-Survey conducted)

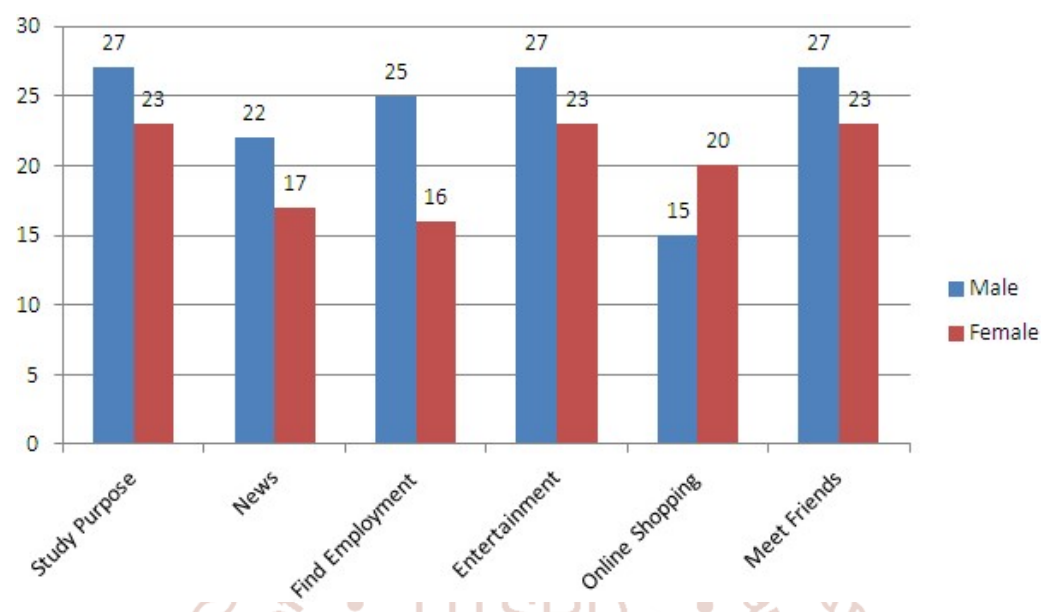

Table no. 2 exhibit data about reason for use of social networks. In case of reasons for using social network for male $54 \%$ and female $46 \%$ students prefer study purpose, for entertainment and meet friends and female. In case of online shopping we found male students are using $43 \%$ and Female students $57 \%$.nd in Scientific

In this conclude that the high use of social media for study purpose, entertainment and to meet friends.

\section{Student's Opinion about Social Networks}

$>$ Social Networks useful in sending academic information.

$>$ For understanding use of latest updates in the study field.

$>$ Helps in exchanging academic ideas and knowledge.

$>$ Social networks have become know a new approach in learning new things in academia.

\section{Conclusion-}

Now a days Social Networks have been become integrated part of student life. Social Networks know have become the most important medium of interaction for keeping in touch with each other, or to communicate with their family members \& friends.

Above study shows that Whatsapp, Facebook and Instagram are most popular Social Networks medium among the student community.

\section{References-}

[1] Boyd, D. and Ellison, N. B. Social network sites: definition, history, and scholarship. Journal of Computer-Mediated Communication, 2007, 13(1), 210230.

http://jcmc.indiana.edu/vol13/issue1/boyd.ellison.ht ml (accessed 15 December, 2015)

[2] Singh, K. P. and Gill, M. S. Use of social networking sites by the research scholars: a study of Guru Nanak Dev University, Amritsar. Library Herald, 2011, 49(3), 229241.

[3] Lemke, C., Coughlin, E., Garcia, L., Reifsneider, D. \& Baas, J., Leadership for web 2.0 in education: Promise and reality. Culver City, CA: Metiri Group, 2009.

Copyright (C) 2019 by author(s) and International Journal of Trend in Scientific Research and Development

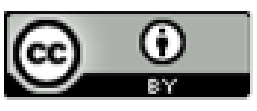
Journal. This is an Open Access article distributed under the terms of the Creative Commons Attribution License (CC BY 4.0) (http://creativecommons.org/licenses/by/4.0) 